Cahiers $d u$ MONDE RUSSE

\section{Cahiers du monde russe}

Russie - Empire russe - Union soviétique et États indépendants

$52 / 4 \mid 2011$

Varia

\title{
Ilya Gerasimov, Jan Kusber, Alexander Semyonov, eds., Empire Speaks Out
}

\section{Daniel Beauvois}

\section{OpenEdition}

\section{Journals}

Édition électronique

URL : http://journals.openedition.org/monderusse/7517

DOI : 10.4000/monderusse. 7517

ISSN : $1777-5388$

\section{Éditeur}

Éditions de l'EHESS

\section{Édition imprimée}

Date de publication : 20 décembre 2011

Pagination : 689-692

ISBN : 978-2-7132-2353-2

ISSN : $1252-6576$

Référence électronique

Daniel Beauvois, « Ilya Gerasimov, Jan Kusber, Alexander Semyonov, eds., Empire Speaks Out », Cahiers du monde russe [En ligne], 52/4 | 2011, mis en ligne le 28 novembre 2012, Consulté le 23 septembre 2020. URL : http://journals.openedition.org/monderusse/7517 ; DOI : https://doi.org/ 10.4000/monderusse. 7517

Ce document a été généré automatiquement le 23 septembre 2020.

(c) École des hautes études en sciences sociales 


\title{
Ilya Gerasimov, Jan Kusber, Alexander Semyonov, eds., Empire Speaks Out
}

\author{
Daniel Beauvois
}

\section{RÉFÉRENCE}

Ilya GeRASImov, Jan KuSBER, Alexander SEMYonov, eds., Empire Speaks Out : Languages of Rationalization and Self-Description in the Russian Empire. Leiden-Boston : Brill, $2009,280 \mathrm{p}$.

L'introduction est signée de cinq des sept auteurs de ce recueil. Ils exposent, comme ils l'avaient fait en russe dans un livre paru en 2004 à Kazan1, et comme l'avait répété I. Gerasimov dans $A b$ Imperio en 2005 ( $\mathrm{n}^{\circ} 1$, p. 33-56), leur volonté d'une "nouvelle histoire impériale » qui repense positivement ce qu'une tradition "outrageusement » axée sur les nations avait trop déprécié. Leur idéal est ostensiblement placé sous le signe des méga-visions et macro-systèmes chers à l'histoire pratiquée aux États-Unis depuis trente ans : des notes surabondantes soulignent cette parenté ou ce patronage. Tous ces auteurs ont travaillé aux États-Unis et beaucoup plus publié en anglais qu'en russe. Ils rejettent les théories qui, depuis le xviII siècle, relient la Russie au « despotisme oriental » et veulent montrer - occidentalistes d'un nouveau genre - que l'Empire russe, en comparaison des empires occidentaux, n'était ni exceptionnel, ni scandaleux. Ils se dissocient des groupes qui, en étudiant l'Empire russe, ne pratiquent pas les rapprochements mondiaux et globalisants : les historiens d'Hokkaïdo autour de K. Macuzato; les auteurs liés aux éditions NLO de Moscou, notamment dans la série Okrainy Rossijskoj imperii (de la collection Historia Rossica), trop russocentriques ; ceux qui, autour d'Indiana University Press, comme Mark von Hagen, font trop de place aux territoires composant l'Empire russe ; ceux enfin, nombreux, qui insistent sur l'histoire religieuse. Les auteurs veulent nous convaincre de la pertinence de leur "approche cognitive ", de la "vérité rhétorique ", placée sous le signe des Scenarios of power de 
Richard Wortman (Princeton, 1995, 2000); mais l'affirmation martelée de leur "relativisme stratégique", censé aboutir à une nouvelle clé de compréhension de l'empire, peut paraître un peu artificielle.

2 Un article également théorique d'Ann Stoler (p. 33-55) vient conforter cette approche qui veut « recadrer» les études impériales. Il s'agit de voir dans les empires non plus seulement des «formations ", mais des « situations » en constante évolution. Ce jeu de concepts, accompagné de larges références aux études coloniales et post-coloniales pratiquées depuis les travaux d'Edward Said, il y a trente ans, cherche des analogies transcontinentales relativisantes, mais c'est à peine si l'empire russe ou soviétique y apparaît. D'intéressantes réflexions sur les ruines et les débris d'empire conduisent au thème des nostalgies, des atlantides, des paradis perdus, si fréquents chez les exdominateurs, mais ces sèches abstractions manquent de chair.

Le reste du livre est plus concret, mais ses thèmes sont disparates.

4 L'Allemand Jan Kusberg propose un texte sur la politique de l'éducation de Catherine II en liaison avec ses projets de «bonne gouvernance » (p.59-88). La volonté de positiver amène ici à donner une importance plus grande aux rêves éclairés du début du règne qu'aux modestes résultats. On ne parle ni de manipulation, ni de propagande. Derrière le faste des cérémonies (R. Wortman toujours), on veut voir une représentation de l'empire multiethnique et de ses catégories sociales. Les voyages en province, les lettres à Voltaire, les instructions pour la Commission législative, la composition de celle-ci, tout concourt à souder l'empire à tous niveaux. De même, la réforme administrative de 1775, guidée par l'idéal du bien public, par le besoin d'écoles, d'hôpitaux, d'orphelinats, ne crée des gubernii dirigées par la noblesse qu'en attendant l'émergence probable d'un tiers-état. Les belles envolées de la correspondance avec Grimm, les écoles militaires, commerciales, et même le manuel des Devoirs de l'homme et du citoyen (1783, réédité 11 fois jusqu'en 1814) sont donnés comme des contributions à la modernisation et au renforcement de la cohésion. C'est se contenter de peu. La glaciation des structures sociales, suite à la Charte de la noblesse de 1785, est prudemment éludée.

5 Un autre Allemand, Hans-Christian Petersen, rappelle (p. 89-119) les différentes manières dont les Polonais absorbés par l'empire ont perçu celui-ci de 1815 à 1863, mais en se limitant au territoire du petit royaume de Pologne, entre 1815 et 1830, puis, au delà, en réduisant la pensée polonaise à celle de l'émigration en France. La téléologie positive amène évidemment l'auteur à vanter la constitution accordée par Alexandre $\mathrm{I}^{\mathrm{er}}$ à Varsovie et l'influence certaine des Polonais slavophiles qui espéraient jouer le rôle des Grecs dans l'empire romain (S. Staszic, A. J. Czartoryski). S'il connaissait l'histoire des provinces lituano-ruthènes annexées à l'empire, H.C. Petersen aurait pu tirer argument des cas de participation de plusieurs grandes familles polonaises à la haute administration ou à l'armée impériale, mais cela n'aurait pas rendu ces collaborations plus significatives, car comment expliquer l'insurrection de 1830-1831? Plus convaincant apparaît son exposé du changement de perspective imposé, après 1831, par les «démocrates nobiliaires " émigrés, au nom de valeurs largement mythiques, mais très mobilisatrices. C'est là l'origine de l'appel aux Russes éclairés : «Pour votre liberté et la nôtre ", resté sans résultat. L'article utilise les travaux connus de L. Kuk, H. Glebocki, ou A. Nowak sur les rapports polono-russes, mais peine à en tirer l'empiriologie positive souhaitée. Quant à la rivalité polono-russe dans la domination de l'Ukraine, elle est perçue à travers le vieil ouvrage de M. Handelsman (1937), ce qui est très insuffisant. L'article aurait plutôt dû montrer qu'il est risqué d'introduire la 
question polonaise dans un ouvrage si orienté vers la recherche d'hypothétiques valeurs impériales de cohésion. Seule la politique culturelle et scolaire avant 1831 l'autorise largement.

6 L'article de Sergey Glebov sur la lente semi-intégration des Iakoutes (p.121-151) montre que la pénétration impériale n'a pas été que gouvernementale, mais souvent privée (trappeurs, marchands), et qu'ici aussi des élites locales ont été attirées et entraînées dans l'orbite du pouvoir. Ici encore, la volonté « civilisatrice » qui a suivi les explorations a induit une inévitable dénaturation des identités premières en imposant des institutions russes (les soslovija, une noblesse imaginaire, une éphémère " douma des steppes", une sédentarisation par le mir), où n'apparaît aucun universalisme impérial. En revanche, la langue iakoute, véhiculée par le cyrillique, a su s'imposer aux Russes mêmes, comme lingua franca dans toute la Sibérie orientale, ce qui démontre, aux yeux de l'auteur, que l'empire n'était pas tellement russificateur.

7 Marina Mogilner (p. 155-189) synthétise les conclusions de son livre Homo Imperii: Istorija fizičeskoj antropologii v Rossijskoj Imperii (Moscou, 2008). Elle retrace excellemment l'essor de cette science à la fin du XIX ${ }^{\mathrm{e}}$ siècle, ce qui n'est pas sans rappeler les travaux récents de Juliette Cadiot. Elle a tendance à magnifier les grands représentants de l'école russe de cette nouvelle branche du savoir, en montrant leur idéalisme positiviste qui n'était pas entaché par les tendances antisémites et xénophobes des années 1870-1890, d'autant plus, dit-elle, que l'État s'intéressait peu à leurs recherches. On peut douter de cette indifférence du pouvoir ou des hautes instances scientifiques quand on sait qu'une science très proche - l'ethnographie - donnait lieu, sous le couvert de l'IRGO, la Société impériale russe de géographie, à des falsifications de statistiques éhontées. Bien que consciente de l'échec du scientisme moral, M. Mogilner s'enthousiasme de ce qu'« aurait pu être » un empire rénové, dont le pluralisme des races eût été basé sur "une plus grande rationalité et une plus grande justice». Effectivement...

8 Également très documenté, le texte d'Alexander Semyonov (p. 197-228) sur la diversité ethnique des première et deuxième doumas apporte des informations variées, puis se concentre sur la tendance universaliste et rationaliste représentée par le parti KD. Le Conseil d'État est évidemment laissé de côté puisque sa composition, basée sur les ordres, ne répond pas à la visée d'une possible modernisation de l'empire. Après un bon rappel des zizanies de classes, de nations, de religions, de régions qui traversèrent ces assemblées, l'auteur semble, lui aussi, découvrir «l'universalité rationnelle» de l'« édifice impérial » tel que le souhaitait F. F. Kokoškin. Une fois encore, il s'agit d'une potentialité quasiment présentée comme un idéal possible de condominium fédératif pour aujourd'hui.

9 Le principal rédacteur du volume, Ilya Gerasimov, ajoute une étude personnelle traitant d'un groupe formé, peu avant la réforme de Stolypin et pendant sa mise en œuvre, par les conseillers en agriculture, en agronomie, les vétérinaires, les coopérateurs, tous les artisans d'une "ingéniérie sociale » qui « eût pu » transformer la société et, comme veut le croire l'auteur, au diapason des articles précédents, forger une société impériale rénovée. Il montre combien ces hommes nouveaux avaient de liens avec un mouvement analogue aux États-Unis, en France et avec tout le scientisme international. Cette utopie d'un socialisme apolitique pouvait, selon ses promoteurs, se fondre dans la mentalité et les réalités du monde du moujik afin de reconfigurer la société, comme l'imaginaient les KD. Cette surestimation du mouvement par l'auteur l'amène à éluder 
son échec et à tomber dans une glorification de Stolypin que l'empire n'a pas su comprendre.

10 Tel qu'il apparait dans le titre du livre et dans son contenu, l'empire ne "parle haut " ici que pour indiquer les chemins potentiels qu'aurait pu suivre la Russie. Mais l'histoire ne peut se contenter de virtualités 